\title{
Optimal Asset Liability Management for Post-retirement stage with Income Protection Product
}

\author{
Thomas Sneddon $^{a}$, Chenming Bao and Zili Zhu ${ }^{\mathrm{a}}$ \\ ${ }^{\mathrm{a}}$ CSIRO Clayton \\ Email: thomas.sneddon@csiro.au
}

\begin{abstract}
Australia has a compulsory defined contribution retirement provision system, whereby employers must con-tribute a proportion of the pre-tax salary of their employees towards an individual account which cannot be accessed until retirement except in extraordinary circumstances. These funds are generally invested in a port-folio of financial assets from which the retiree may draw throughout retirement. Retirees under this system face two key problems when making investment and withdrawal decisions regarding this portfolio. Firstly, retirees must manage their superannuation investment portfolio to maximise their riskadjusted returns and thereby best financially provide for their own retirement. Secondly, retirees must optimise their withdrawal pattern from the superannuation account throughout retirement so as to maximise their post-retirement lifetime utility given the need to minimise the risk of portfolio ruin prior to death.

We model this issue as a dynamic stochastic optimisation problem with constraints. The market value of the portfolio is a function of the annual contributions invested by the individual throughout their career and the returns derived from their investment in uncertain financial markets. The post-retirement lifetime utility function is a function of discounted annual income throughout retirement and is therefore subject to market and inflation risk. We model the financial market uncertainties as correlated stochastic processes as projected by a variant on the Wilkie stochastic investment model developed within CSIRO, the SUPA (Simulation of Uncertainty for Pension Analysis) model. We also define an income protection asset (an inflation index linked annuity) which is available to the individual as a tool to hedge inflation risk. We then solve the dynamic superannuation/pension portfolio optimisation problem using a numerical approach that is based on the stochastic control algorithm to calculate the conditional value functions of investors for a sequence of discrete decision dates. The algorithm provides optimal decisions for portfolio asset allocation in financial markets and the optimal amount to shift towards the annuity product on an annual basis to achieve maximum post-retirement lifetime utility whilst minimising the risk of portfolio ruin prior to death.
\end{abstract}

Keywords: Portfolio optimization, least-squares Monte Carlo, approximate stochastic dynamic programming, optimal asset allocation, asset liability management 
T. Sneddon et al., Optimal Asset Liability Management for Post-retirement stage with Income Protection ...

\section{THE FraMEWORK}

\subsection{Asset Liability Model}

The concept behind the asset-liability model is that the investor must meet their annual withdrawal cash flow requirement each year, through a combination of the sale of investment portfolio assets and the income derived from their annuity portfolio (supplemented by age pension income). The investor must also ensure that they do not outlast their investment wealth, and must therefore "convert" their investment portfolio assets into annuity products until the entire annual withdrawal requirement is met by annuity portfolio income and pension income. Further, they must do so in a manner which maximises their lifetime utility according to the utility function outlined below.

The annual withdrawal cash flow requirement is intended to represent a realistic estimate of the financial requirements of an average individual in retirement. For the test case of this paper, the initial withdrawal requirement of an individual will be set as $\$ 42,254$, as outlined in the Australian Superannuation Fund Association's "comfortable lifestyle" retirement standard for 2014: see [1]. The size of each subsequent withdrawal is equal to the withdrawal amount of the immediately preceding year inflated by the price inflation as projected by the SUPA model of this paper.

The starting balance of the investment portfolio is assumed to represent the total wealth of the investor at the age of retirement, and it is assumed that the market for the assets within this portfolio are perfectly liquid in that the investor can instantly purchase or sell such assets instantaneously. This initial wealth can be set as the average superannuation account balance of a 65-69 year old male of $\$ 172,767$ or the equivalent figure for females of $\$ 90,185$ : see [6]. Within this paper, we set this figure at $\$ 1,000,000$, approximately the superannuation fund balance of a 65 year old retiree who has contributed $12 \%$ of their salary throughout a 40 year career under realistic conditions (3.5\% annual wage inflation, $2.5 \%$ annual price inflation and $8 \%$ annual superannuation fund investment return).

\subsection{The investor's problem}

We consider the planning time horizon with maturity date $T$, and the portfolio can be rebalanced at a sequence of dates $0=t_{0}<t_{1}<t_{2}<\ldots<t_{F}=T$. For the purposes of this paper, we have selected $T=30$ as this would bring the retiree to age 95, the 99th percentile of male lifespan in Australia according to the most current life tables [14]. The investor operates the portfolio in order to maximize a "utility function" in the form of a function of portfolio value at the maturity time $T$ :

$$
V_{t}\left(\omega_{t}\right)=\max _{\left.\left\{x_{s} \in \Theta\right\}\right|_{s=t} ^{t_{F-1}}} \mathbb{E}\left[u\left(W_{T}\right)\right], \omega_{t} \in \mathcal{F}_{t}
$$

where $x_{t}$ is a vector of portfolio positions of the $N$ assets at time $t$ and $\Theta$ represents all possible portfolio positions and is called the strategy set. $W_{t}$ is the value of the portfolio(wealth) at time $t . V_{t}$ is the value function at time $t$ with a boundary condition at the maturity date of $T: V_{T}\left(\omega_{T}\right)=\mathbb{E}\left[u\left(W_{T}\right)\right]$ a.s.. The value function $V_{t}$ represents the expectation at time $t$, conditional on the information filtration $\mathcal{F}_{t}$, of the utility of terminal portfolio value $u\left(W_{T}\right)$ given all the subsequent optimal portfolio positions $x_{s}, s=t, \ldots, t_{F}$ The utility function $u(\cdot)$ represents the investor's preference of the portfolio performance; this will be discussed further in Section 2

The investor's problem can be better understood by expressing Equation (1) as a single-period recursive form with value function $V_{t+1}$ and current portfolio value $\Phi_{t}$ :

$$
V_{t}\left[W_{t}, \omega_{t}\right]=\max _{x_{t} \in \Theta}\left\{\mathbb{E}\left[V_{t+1}\left[W_{t} \exp ^{r_{t}\left(x_{t}, W_{t}, \omega_{t}\right)}-L_{t}\left(x_{t}, W_{t}, \omega_{t}\right), \omega_{t+1}\right] \mid \mathcal{F}_{t}\right]\right\}, \omega_{t} \in \mathcal{F}_{t}
$$

where $r_{t}\left(x_{t}, W_{t}\right)$ is the investment returns of the portfolio from time $t$ to $t+1$. The value function $V_{t}$ can be seen as the expected total future utility of the investor at time $t$ with condition that all the portfolio position weights $x_{t}, x_{t+1}, \ldots, x_{T-1}$ are optimally chosen with respect to to all random events $\omega_{s} \in \mathcal{F}_{s}, s=t, t+$ $1, \ldots, T$.

\subsection{Constructing the Strategy Set}

The position vector is $x_{t}=\left\{x^{\{d\}}, x^{\{i\}}\right\}$, where $x^{\{d\}}$ and $x^{\{i\}}$ are percentage weight invested in (Australian) domestic equities and (non-Australian) international equities at time $t . L_{t}$ represents the inflation-adjusted 
T. Sneddon et al., Optimal Asset Liability Management for Post-retirement stage with Income Protection ...

Table 1. Strategy set for 4-step discrete case.

$$
\begin{array}{lll}
x^{(1)}:(0.00,0.00,1.00) & x^{(2)}:(0.00,1.00,0.00) & x^{(3)}:(1.00,0.00,0.00) \\
x^{(4)}:(0.00,0.50,0.50) & x^{(5)}:(0.50,0.50,0.00) & x^{(6)}:(0.50,0.00,0.50) \\
x^{(7)}:(0.00,0.25,0.75) & x^{(8)}:(0.00,0.75,0.25) & x^{(9)}:(0.25,0.00,0.75) \\
x^{(10)}:(0.25,0.75,0.00) & x^{(11)}:(0.75,0.25,0.00) & x^{(12)}:(0.75,0.00,0.25) \\
x^{(13)}:(0.25,0.25,0.50) & x^{(14)}:(0.25,0.50,0.25) & x^{(15)}:(0.50,0.25,0.25)
\end{array}
$$

withdrawal amount which has not been covered by annuity. For example, $L_{t}=42,254 * C P I(t)$ if the retiree hasn't purchased any annuities, where $C P I(t)$ is the consumer price index value at time $t$ relative to $t_{0}$. If the retiree has purchased annuities to cover $10,000 * C P I(t)$ in the previous period $t-1$, then in the next period $L_{t}=(42,254-10,000) * C P I(t)=32,254 * C P I(t)$

We discretise the position weight $x^{\{d\}}, x^{\{i\}}$ of the domestic equities and international equities in the following way: an $m$-step discrete grid is used to represent the portfolio weight as $\left(0, \frac{1}{m}, \frac{2}{m}, \ldots, 1\right)$. The discretised portfolio weight vector $x$ is then defined as all possible combinations of the discrete portfolio weight values for all individual assets. The condition that $x^{\{d\}}+x^{\{i\}}=1$ is also enforced.

The investor thus has a set of possible portfolio positions in vector form, and each of the possible portfolio weight combinations represents a so-called strategy. The full set of strategies for possible adoption can be listed as $\Theta=\left\{x^{(1)}, x^{(2)}, x^{(3)}, \ldots\right\}$. As an example, for a portfolio with 3 assets to invest, each asset weight is discretised by a 4-step grid (i.e. $0 \%, 25 \%, 50 \%, 75 \%$ and 100\%), a total of 15 possible strategies can be chosen. We list some of the strategies in Table 1 as an example.

We assume that at each portfolio rebalancing time $t, t=0,1, \ldots, T-1$, the investor makes a decision to adjust the weight of the position weights between domestic equities and international equities. The position weight after adjustment is chosen from the possible weights pairs of $x^{\{d\}}, x^{\{i\}}$ within the strategy set $\Theta$. In addition, the investor may decide to decrease the liability level $L_{t+1}$ by purchasing annuities. The cost that the investor pays for purchasing annuities is assumed to be taken from the part of the portfolio invested in domestic equities and international equities respectively with ratio $x^{\{d\}}: x^{\{i\}}$. By doing so, the dollar value invested in the domestic equities and international equities is reduced but the percentage weight vector $\left\{x^{\{d\}}\right.$, $\left.x^{\{i\}}\right\}$ after purchasing annuities doesn't change.

\section{A Case Study of Post-Retirement Portfolio Management}

We consider a retiree who manages his/her superannuation portfolio invested in two major equity markets the domestic share market, and the international share market. The investor operates the portfolio from the viewpoint of the home currency. In this paper we assume the Australian Dollar (AUD) as the home currency; thus the international share market asset would be converted into Australian dollars.

The policyholder has initial capital of $\mathrm{AU} \$ 1,000,000$ at age 65 . The policyholder has an annual liability/expenditure to withdraw from the superannuation portfolio. The amount of this annual liability at the start of the planning period is $\$ 42,254$. Apart from the equity markets, there is an inflation index-linked annuity instrument that is used to hedge the liability/expenditure. The policyholder can purchase the annuity at each time step to hedge some or all of his/her liability risk. The optimal decision is on when to purchase the annuity and by how much.

\subsection{The SUPA model}

Projection of the stochastic behaviour of each relevant economic variable will be generated by the SUPA (Simulation of Uncertainty for Pension Analysis) model developed by CSIRO for the CSIRO-Monash Superannuation Research Cluster. These variables are: price inflation, wage inflation, interest rates, domestic market equity returns, foreign market equity returns, domestic bond returns, foreign bond returns and domestic cash investment returns.

The SUPA model utilises a cascade structure to simulate economic variable behaviour in accordance with past long-term relationships between the various elements of the model, whereby each economic variable is influenced by both its own past behaviour and the behaviour of other economic variables within the model. This structure is presented in the figure below. Through application of the SUPA model in accordance with 
the cascade structure, we can simulate more realistic scenarios that can be used directly for the asset-liability management.

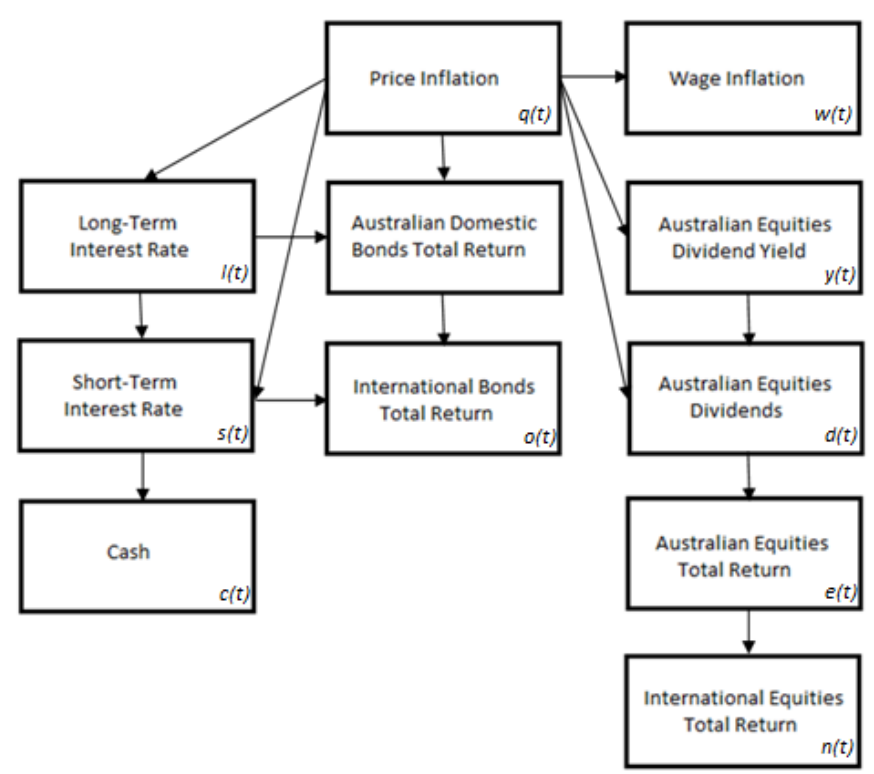

Figure 1. The "cascading" structure of the SUPA model

\subsection{Transaction Cost}

We assume a 50 basis points proportional transaction cost rate charged on absolute turnover of the book size between domestic shares and international shares at every re-balancing time $t$, given by

$$
T C_{t}=0.5 \% \Sigma_{i=1}^{N}\left|\Phi_{i}(t+)-\Phi_{i}(t)\right|,
$$

where $N$ is the number of assets in the portfolio, $\Phi_{i}(t)$ is the position in the asset $i$ at time $t$ before rebalancing and $\Phi_{i}(t+)$ is the position of the asset $i$ at time $t$ after re-balancing. We ignore any slippage for the re-balancing and assume no short selling and borrowing for all the asset classes.

\subsection{Annuity price model}

Annuities are assumed to be priced by reference to the initial annual income provided to the investor on purchase. Specifically, the annuity is assumed to initially pay an income $\$ X$ equal to a certain percentage (C) of the purchase price $(\mathrm{P})$; therefore the price for an annuity paying $\$ \mathrm{X}$ initially is $\mathrm{P}=(\mathrm{X} / \mathrm{C})$ where $\mathrm{C}$ is determined by reference to a schedule based upon the age of the investor at the time of annuity purchase. Table 2 below is a schedule replicating promotional material of a major bank in Australia in 2014: see [7]. The investor can purchase an annuity paying $\mathrm{C}=4 \%$ of purchase price between ages 55 and 64 (i.e. initial annual payment $=0.04 \mathrm{P}$ such that an annuity initially paying $\$ 30,000$ would be purchasable for $P=(X / C)=(30,000 / 0.04)=\$ 750,000)$. It is also assumed that all annuities are price inflation-linked, such that later payments from an annuity are inflated by the level of price inflation within the economy throughout the previous time step (as projected by the SUPA model).

\subsection{Investor's utility}

We consider different risk preference types of investors by defining the investors' utility functions as in Equation (1). The utility function we used in this case study is a risk aversion utility function, the Exponential function, which is given by:

$$
u(w)=\exp \{-\alpha \cdot w\}, \quad \alpha>0,
$$


T. Sneddon et al., Optimal Asset Liability Management for Post-retirement stage with Income Protection ...

Table 2. Initial price of inflation-linked life annuity.

$\begin{array}{rccccccc}\text { Age } & 55-64 & 65-74 & 75-79 & 80-84 & 85-89 & 90-94 & 95+ \\ \text { Initial \% of purchase price paid (C) } & 4 \% & 5 \% & 6 \% & 7 \% & 9 \% & 11 \% & 14 \%\end{array}$

\subsection{Optimal Switching and Least Squares Monte Carlo Scheme}

In this section we describe the approximation algorithm we use to estimate the expected value function in Equation (1). We extend the Least Squares Monte Carlo framework introduced in [12] to a multiple switching scheme. The inputs to the LSMC model are:

- 15,000 Monte Carlo simulated sample paths of the international equity total returns, Australian equity total returns and inflation rate generated by the SUPA model at time $t=0,1,2, \ldots, 30$, $\left\{e^{(k)}(t), n^{(k)}(t), q^{(k)}(t)\right\}, k$ is the sample path's number and $t$ is the time index. The first 5,000 sample paths is the training set for the investment portfolio invested in Australian equities and international equities, the next 5,000 sample paths is used in solving the optimal switching problem between equity portfolio and annuities. The remaining 5,000 paths are for out-of-sample testing. This number of sample paths was chosen as the most computationally efficient for solving the problem at this stage, future work will examine the efficacy of increasing path numbers.

- A transaction cost function $T C\left(x_{t-1}, x_{t}, \omega_{t}\right)$;

- The annuity pricing model given in subsection 2.3

The first step is to decide the optimal investment weight for the equity portfolio invested in Australian equities and international equities. We follow the methodology described in [4] which builds upon the work of [2]. We use the first 5,000 sample paths to calibrate the optimal weights. This calibration step requires performing least squares regressions at each time step to compute the continuation value for each strategy. The regression is performed via a basis function choice of polynomials truncated to third order. Then for any random sample paths of Australian equity returns and international equity returns, we are able to compute the optimal weights and calculate the total return of the equity portfolio with transaction costs for this particular sample path.

Next, we solve Equation 2 recursively. Here the equity portfolio value $W_{t}$ and the outstanding liability $L_{t}$ are dependent on the previous decisions $x_{s}, s=0,1, \ldots, t-1$. We make $W_{t}$ and $L_{t}$ as two extra state variables by randomly generating decisions of purchasing annuities for all of the 10,000 sample paths in the training set. We then calculate the optimal switching strategy from equity portfolio to the annuities.

\section{RESULTS AND DiscuSSION}

The algorithm presented here is implemented in the software package RiskLab, for computing the numerical results in this section ${ }^{1}$. Once the model parameters of the relevant risk factors are calibrated, we can calculate all the expected value functions at any future asset prices for all the portfolio strategies. At time $t$, if the previous strategy at time $t-1$ is known, we can readily select the current optimal target portfolio strategy. In other words, the algorithm can be used as a what-if forecasting tool for portfolio strategies. For example, for any given scenario of risk factors the current methodology produces optimal portfolio weights at every re-balancing date for given scenario events.

The first result we looked at was the probability of shortfall (POSF). Here we define the probability of shortfall as the number of scenarios within the total of 5000 simulations within which the investors' balance falls below 0 during their retirement. The POSF for an investor without annuities as part of their portfolio is $13.2 \%$, while for an investor with annuities the POSF is reduced to $7.6 \%$.

Figure 2 shows the probability densities for both without and with annuities investment strategies. The dotted horizontal lines are the $5 \%$ quantiles for each of the case. From this graph, it is easily seen that the use of annuities shifts the whole density plot to the right. By dynamically purchasing annuities within the postretirement investment time period, an investor can control or reduce their risk of fund ruin during retirement.

${ }^{1}$ RiskLab is a software package developed by CSIRO for asset modelling, simulation, decision supporting, real option pricing and portfolio optimization. 
T. Sneddon et al., Optimal Asset Liability Management for Post-retirement stage with Income Protection ...

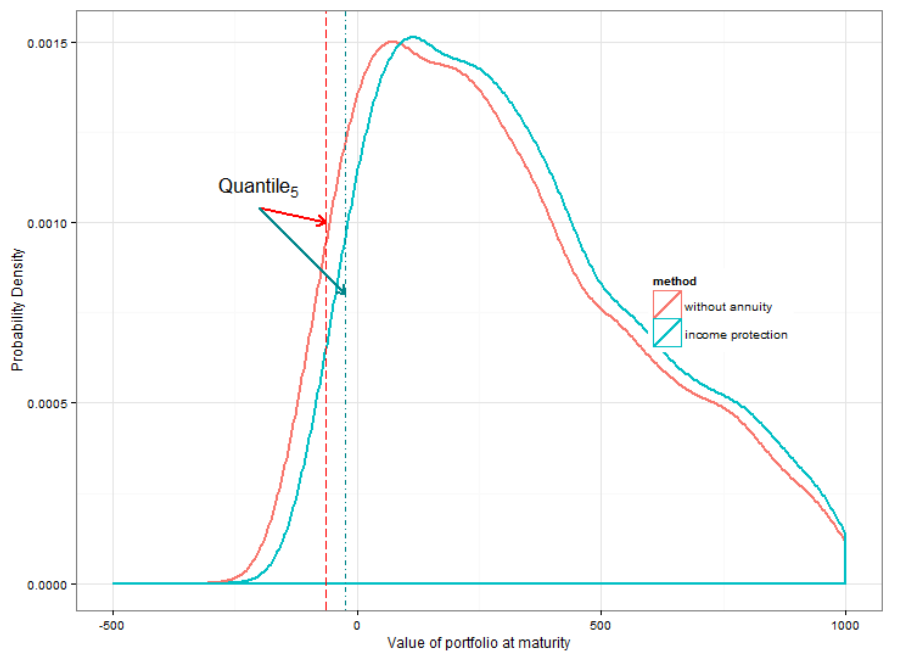

Figure 2. The probability distribution of future portfolio values for strategies with and without annuities.
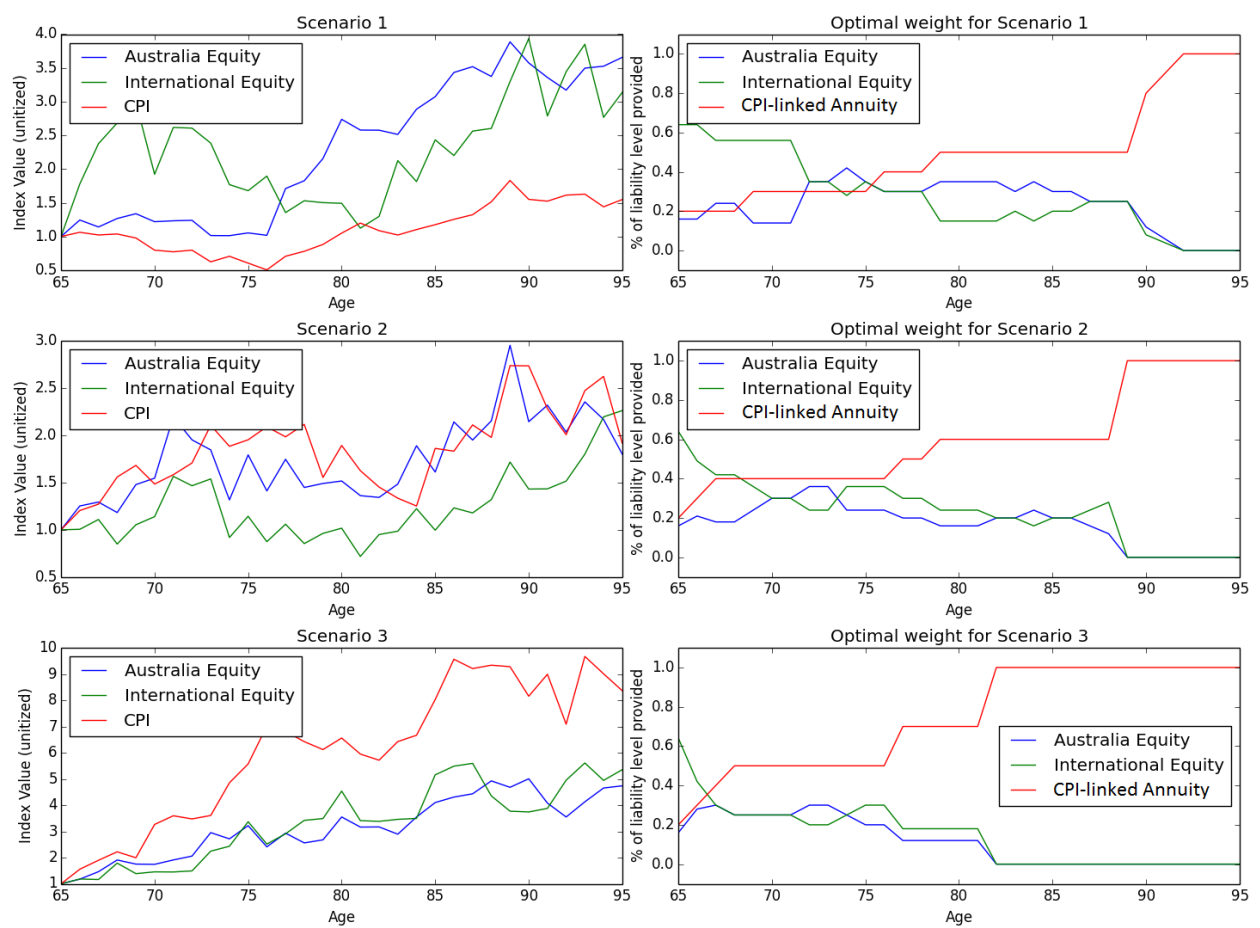

Figure 3. Dynamic optimal portfolio strategies for three illustrative scenarios.

Although retirees with different risk preferences will arrive at different decisions (optimized portfolio weights), on the assumptions made in this paper the initial decision for the retiree at age 65 is a portfolio that holds annuities that can provide $10 \%$ of retiree's liability ( $10 \%$ of $\$ 42,254 * C P I(t)$ ) for their life time. The rest of the fund is invested in the equity portfolio, $80 \%$ in international equities and $20 \%$ in Australian equities.

Figure 3 displays the optimal rebalancing strategies for three different scenarios representing different economic circumstances. Scenario 1 shows a "boom" period where equity performance far exceeds inflation. 
Scenario 2 represents a neutral period where low equity returns roughly equate with a "normal" level of inflation. Scenario 3 displays a "correction" period where equities underperform the inflation rate.

It can be seen within the scenarios that as return on international equities is expected to exceed Australian equities returns and CPI change, each optimal portfolio strategy begins with a higher weighting in international equities than other assets. Further, in each scenario the optimal portfolio strategy entails gradual increases in weight in the CPI-linked annuity through time as the CPI increases, leading to full weighting in the CPI-linked annuity at $\mathrm{T}$ in each scenario. The general trend of the strategies demonstrates the added value provided by the dynamic inclusion of annuity assets within retiree portfolios. It is notable that the rate of increase in weight in the CPI-linked annuity is driven by the relative performance of the CPI itself compared to equity returns.

\section{REFERENCES}

[1] Association of Superannuation Funds of Australia (ASFA). 2014. ASFA Retirement Standard. [ONLINE] Available at: http://www.superannuation.asn.au/resources/retirement-standard. [Accessed 12 May 14].

[2] Bao, C., M. Mortazavi-Naeini, S. Northey, T. Tarnopolskaya, A. Monch and Z. Zhu "Valuing flexible operating strategies in nickel production under uncertainty", in 20th International Congress on Modelling and Simulation. Modelling and Simulation Society of Australia and New Zealand, December 2013,, pp. 1426-1432. ISBN: 978-0-9872143-3-1.

[3] Bao, C. and Z. Zhu "Land use decisions under uncertainty: optimal strategies to switch between agriculture and afforestation", in 20th International Congress on Modelling and Simulation. Modelling and Simulation Society of Australia and New Zealand, December 2013, pp. 1419-1425. ISBN: 978-0-9872143-3-1.

[4] Bao C., Z. Zhu, N. Langrené and G. Lee "Multi-period dynamic portfolio optimization through least squares learning", in IAENG Transactions on Engineering Sciences, 2014, pp. 29-42. ISBN: 978-9814667-35-7.

[5] Brandt, M.W., A. Goyal, P. Santa-Clara and J.R. Stroud "A Simulation Approach to Dynamic Portfolio Choice with an Application to Learning About Return Predictability", in Review of Financial Studies 18, 2005, pp. 831-873.

[6] Clare, R. 2014. An update on the level and distribution of retirement savings. [ONLINE] Available at: http://www.superannuation.asn.au/ArticleDocuments/1089/1403LevelAndDistributionRetirementSavings.pdf.aspx. [Accessed 12 May 14]

[7] Commonwealth Bank of Australia. 2014, Guaranteed annuities: Lifestream Guaranteed Income (Product Disclosure Statement). [ONLINE] Available at: https://www.commbank.com.au/personal/applyonline/download-printed-forms/PDS-Annuties-CIL1220-CIL80.pdf. [Accessed 02 October 2014].

[8] Consigli, G. and M.A.H. Dempster, "Dynamic stochastic programming for asset-liability management", in Annals of Operations Research 06-1998, Volume 81, Issue 0, , pp. 131-162.

[9] Dempster, M.A.H., M. German, E.A. Medova and M. Villaverde "Global Asset Liability Management", in British Actuarial Journal, 9, pp 137-195 doi:10.1017/S1357321700004153.

[10] Fama, E.F. and K.R. French "The Cross-Section of Expected Stock Returns", The Journal of Finance, number. 2, volume XLVII, June 1992 pp 427-465.

[11] Grinold, R. and R. Kahn. “Active Portfolio Management: A Quantitative Approach for Producing Superior Returns and Controlling Risk,(2nd ed.)" McGraw-Hill, 1999.

[12] Longstaff, F.A. and E.S. Schwartz. "Valuing American options by simulation: A simple least-squares approach", Review of Financial studies, number. I, volume 14, 2001 pp 113-147.

[13] Stentoft, L. "Assessing the Least Squares Monte-Carlo Approach", Review of Derivatives Research, number. 7, 2004 pp 129-168.

[14] The Australian Government the Treasury. 2014. Australian Life Tables 2010-12. [ONLINE] Available at: http://www.aga.gov.au/publications/life_table_2010-12/. [Accessed 13 June 15]. 